\title{
SISTEM INFORMASI KELOMPOK TANI BERBASIS ANDROID (SI POKTAN BERANI)
}

\author{
Jansen Pratama Setiawan L.T ${ }^{1}$, Jilan Jamilah ${ }^{2}$, Risyanto ${ }^{3}$, Eni Heni Hermaliani ${ }^{4}$, Daning Nur \\ Sulistyowati ${ }^{5}$
}

${ }^{1,2,3,5}$ Sistem Informasi, STMIK Nusa Mandiri

${ }^{4}$ Ilmu Komputer, STMIK Nusa Mandiri

\section{Article Info:}

Dikirim: 27 September 2020

Direvisi: 10 Desember 2020

Diterima: 30 Desember 2020

Tersedia Online: 31 Desember 2020

Penulis Korespondensi:

Jansen Pratama Setiawan L.T Sistem Informasi, STMIK Nusa

Mandiri, Jakarta, Indonesia

Email: jansentobing0@gmail.com

\begin{abstract}
Abstrak: Dengan berkembangnya teknologi yang begitu cepat, sistem informasi kini sudah berkembang dan terbukti sangat berperan penting dalam berbagai organisasi. Setiap jenis organisasi sangat terbantu dengan adanya sistem infomasi dalam berbagai aspek seperti meningkatkan efisiensi dan efektivitas operasional organisasi. Beberapa organisasi non-formal seperti kelompok tani yang kebanyakan masih menggunakan sistem manual baik dalam hal pendataan secara rinci setiap anggotanya, pembuatan laporan, serta penyampaian informasi yang bisa saja berbeda setiap anggota. Karena masih menggunakan sistem manual seperti ini, beberapa laporan yang penting bisa saja hilang, pelayanan yang tidak efesiensi dan membutuhkan waktu yang lama. Maka itu dibuatlah aplikasi berbasis android yaitu Si Poktan dan AA Poktan, karena sudah banyak pengguna telepon genggam android. Dan dengan menggunakan aplikasi berbasis android pada kelompok tani ini, dapat memudahkan segala kegiatan dalam kelompok tani.
\end{abstract}

Kata kunci: android; sistem informasi; waterfall; kelompok tani.

\begin{abstract}
With the rapid development of technology, information systems have now developed and have proven to be very important in various organizations. Every type of organization is greatly helped by the existence of information systems in various aspects such as increasing the efficiency and effectiveness of the organization's operations. Several non-formal organizations such as farmer groups, which mostly still use manual systems, both in terms of detailed data collection for each member, preparation of reports, and delivery of information that may vary for each member. Because they still use a manual system like this, some important reports can be lost, services are inefficient and take a long time. So an Android-based application was made, namely Si Poktan and AA Poktan, because there are already many Android mobile phone users. And by using an Android-based application on this farmer group, it can facilitate all activities within the farmer group.
\end{abstract}

Keywords: android; information system; waterfall; farmer group. 


\section{PENDAHULUAN}

Sistem informasi berperan penting dalam operasional organisasi nonformal seperti kelompok tani. Saat ini masih banyak kelompok tani yang pengoperasiannya masih menggunakan sistem manual, baik itu dalam hal pendataan serta penyebaran informasi. Akibatnya, sering terjadi masalah seperti tidak kembalinya barang yang dipinjamkan, inkonsistensi data, dan informasi yang tidak tepat. Sistem yang sudah terkomputerisasi dengan baik adalah salah satu alternatif pemecahan masalah tersebut karena proses pengolahan data dapat dilakukan lebih cepat dan tepat serta dapat mengurangi kesalahan-kesalahan akibat pencatatan manual.

Penelitian terkait dimana suatu organisasi yang dalam semua proses kegiatan administrasinya masih dilakukan secara manual akhirnya membutuhkan sebuah aplikasi administrasi agar seluruh proses kegiatannya dapat dilakukan secara real time dimana saja dan juga dapat meningkatkan kinerja proses kegiatan menjadi lebih efektif dan efisien. Dapat disebutkan bahwa dengan adanya sistem terkomputerisasi membuat semua proses input-output data menjadi lebih efektif dan efisien, dapat diakses dengan mudah, dan proses pelaporan menjadi lebih baik dengan adanya fitur cetak laporan secara langsung.

Sistem yang menggunakan basis android dapat memberikan informasi secara valid dan memberikan kemudahan dalam mengakses informasi selama perangkat terhubung dalam jaringan internet. Dengan memanfaatkan perkembangan teknologi informasi yang kian pesat dimana hampir semua kalangan kini sudah menggunakan ponsel pintar (smartphone), maka dibuatlah aplikasi sistem informasi kelompok tani berbasis android yang bernama POKTAN (Kelompok Tani).

\section{METODOLOGI PENELITIAN}

Metode perancangan pada sistem menggunakan Unified Modelling Language (UML) dan dalam perancangan sistem menggunakan metode waterfall. Dalam pengujian sistem ini menggunakan Black Box Testing, seperti proses login, pengelolaan data dalam si poktan dan pelaporan pada setiap pengguna.

\section{HASIL DAN PEMBAHASAN}

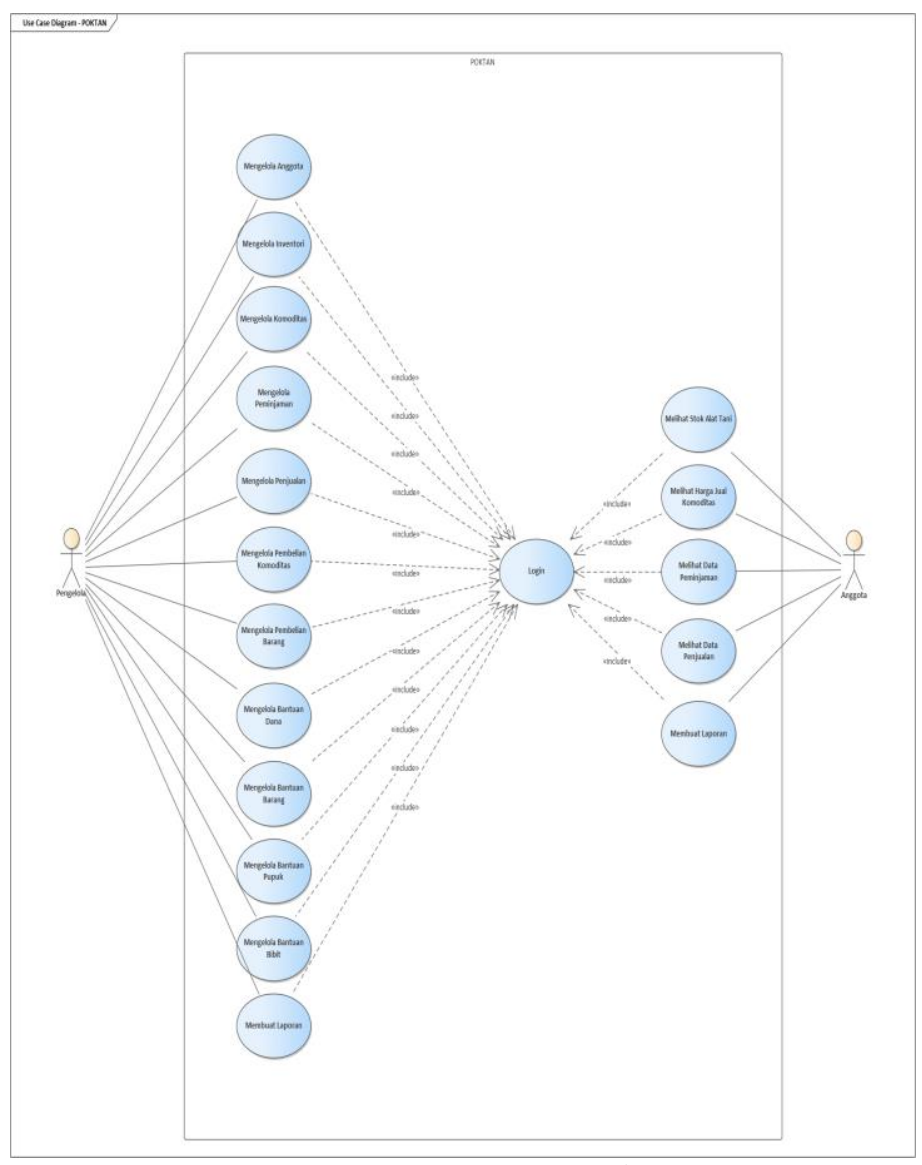

Gambar 1. Usecase Sistem SI Poktan 


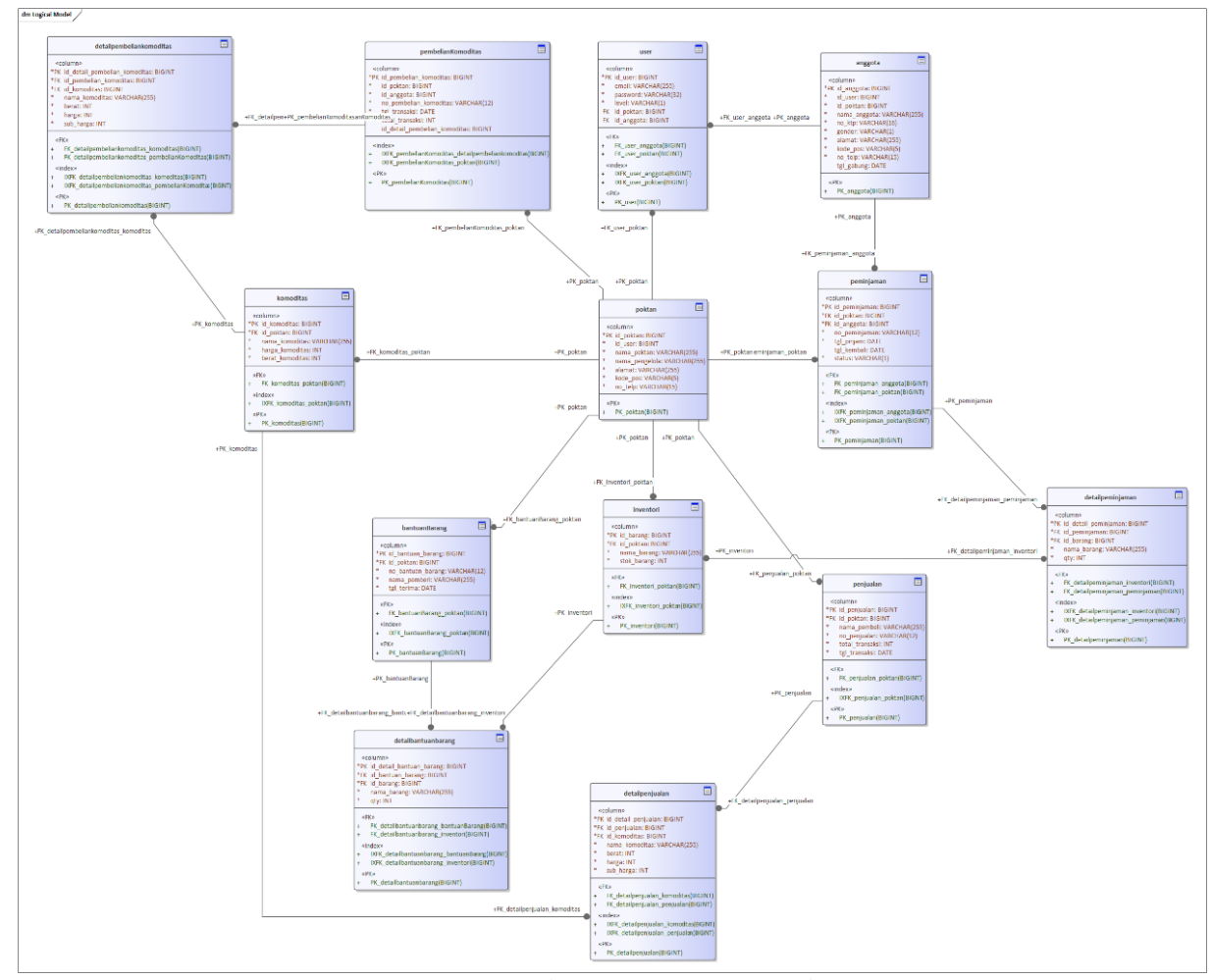

Gambar 2. Class Diagram SI Poktan

Berikut tampilan user interface dari si poktan dan aa poktan
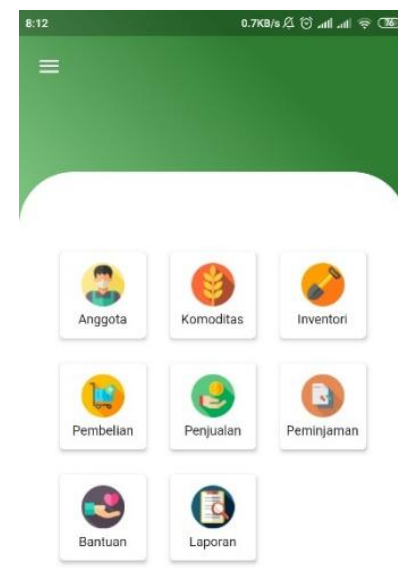

\section{Gambar 3. Menu Utama SI POKTAN}

Gambar 3 diatas menunjukkan implentasi menu utama dari si poktan yang digunakan oleh admin atau ketua dalam kelompok tani. Tampilan ini memiliki menu yang dapat membantu ketua kelompok tani seperti, melihat informasi setiap anggota yang tergabung dalam kelompoknya, ketua dapat memantau setiap anggota yang melakukan setiap peminjaman berupa barang, dana, bibit, ketua dapat membuat harga setiap komoditas sesuai kesepekatan. 


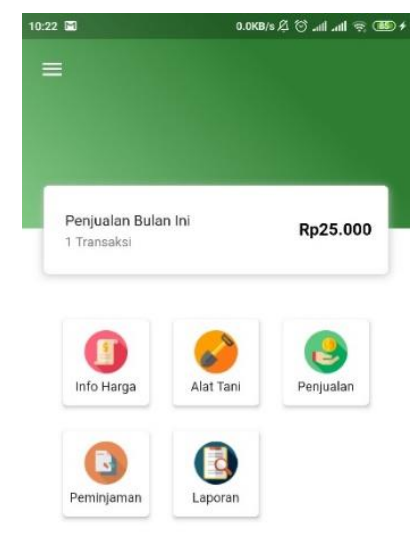

\section{Gambar 4. Menu Utama AA POKTAN}

Gambar 4 diatas adalah implementasi menu utama dari aa poktan yang digunakan oleh anggota kelompok tani yang telah bergabung dalam suatu kelompok. Tampilan ini memiliki menu-menu yang dibutuhkan oleh anggota seperti, anggota dapat mengetahui harga dari setiap komoditas, anggota dapat melakukan peminjaman barang maupun dana.

\section{KESIMPULAN}

Menggunakan metode waterfall sangat tepat dalam pembuatan sistem aplikasi berbasis android, dikarenakan mempunyai struktur yang kompleks dan tepat dengan masalah yang dihadapi oleh kelompok tani. Aplikasi SI POKTAN dan AA POKTAN dapat mempermudah kelompok tani dalam melakukan pendataan diri secara rinci serta tidak khawatir jika laporan akan hilang. Informasi yang didapat juga sama semua, antara setiap anggota kelompok sehingga tidak akan menimbulkan kesalahpahaman.

\section{DAFTAR PUSTAKA}

[1] I. Carolina, K. Ramanda, A. Rusman, and I. Akbar, "Rancang Bangun Aplikasi Stock Opname Pada Pt. Arie Muti Berbasis Android," INTI Nusa Mandiri, vol. 14, no. 1, pp. 1-6, 2019, doi: 10.33480/INTI.V14I1.544.

[2] Nurasiah, A. Irmayanti, A. Akbar, and Budiman, "Aplikasi Administrasi Petani Salak di Desa Kaliurang Magelang berbasis-Web,” ISSN 2477 - 2097, vol. 3, pp. 181-190, 2017.

[3] Christian, Ade and F. Ariani, "Rancang Bangun Sistem Informasi Peminjman Perangkat Demo Video Confrence Berbasis Web Dengan Metode Waterfall," PILAR Nusa Mandiri vol. 14, No 1 Maret 2018 , vol. 14, no. 1, pp. 109-111, 2018.

[4] A. D. B. Sadewo, E. R. Widasari, and A. Muttaqin, "Perancangan Pengendali Rumah menggunakan Smartphone Android dengan Konektivitas Bluetooth,” J. Pengemb. Teknol. Inf. dan Ilmu Komput., vol. 1, no. 5, pp. 415-425, 2017.

[5] A. N. Fiqri, N. Zen, R. A. Azmmi, S. Anggraeni, and I. Engineering, "Seblak Application " News About the Accident " Android," vol. 16, no. 2, pp. 139-146, 2019.

[6] A. R. Hakim, K. Harefa, and B. Widodo, "Pengembangan Sistem Informasi Akademik Berbasis Android Menggunakan Flutter Di Politeknik," SCAN - J. Teknol. Inf. dan Komun., vol. 14, no. 3, pp. 27-32, 2019, doi: $10.33005 /$ scan.v14i3.1684.

[7] D. Mahdiana, "Pengadaan Barang Dengan Metodologi Berorientasi Obyek: Studi Kasus Pt . Liga Indonesia," J. Telemat., vol. 3, no. 2, pp. 36-43, 2016.

[8] G. W. Sasmito, "Penerapan Metode Waterfall Pada Desain Sistem Informasi Geografis Industri Kabupaten Tegal,” J. Inform. Pengemb. IT, vol. 2, no. 1, pp. 6-12, 2017.

[9] M. Susilo, "Rancang Bangun Website Toko Online Menggunakan Metode Waterfall," InfoTekJar (Jurnal Nas. Inform. dan Teknol. Jaringan), vol. 2, no. 2, pp. 98-105, 2018, doi: 10.30743/infotekjar.v2i2.171. 